\title{
CORRELATION OF PLATELET VOLUME INDICES (PVI) WITH SPECTRUM OF CORONARY ARTERY DISEASE: A PROSPECTIVE STUDY IN INDIAN SCENARIO
}

\author{
Rigvardhan', Nikhilesh Kumar², Rama Girish ${ }^{3}$, Nishant Taur 4 , Jyoti Kotwal5 \\ ${ }_{1}^{1}$ Associate Professor, Department of Pathology, Command Hospital, Lucknow. \\ 2 Professor, Department of Pathology, Command Hospital, Lucknow. \\ 3 Professor, Department of Cardiology, Command Hospital, Lucknow. \\ 4 Junior Resident, Department of Pathology, Command Hospital, Lucknow. \\ ${ }^{5}$ Consultant, Department of Haematology, Sir Ganga Ram Hospital, New Delhi.
}

\section{ABSTRACT}

\section{BACKGROUND}

Coronary artery disease is new epidemic of the current millennium and is the leading cause of death worldwide. Platelet size reflects its activity and have definitive role in causing its pathogenesis and its complications as larger platelets are metabolically and enzymatically more active. The aim of this study was to study Platelet Volume Indices (PVI) in the spectrum of coronary artery diseases.

\section{METHOD AND MATERIALS}

In this prospective study, 230 cases were studied. Group I- 100 patients with acute myocardial infarction (AMI) or unstable angina (UA). Group II-100 patients had stable coronary artery disease. Group III - 30 healthy and age matched controls from health checkup with no history of heart disease and normal electrocardiogram. The anticoagulated peripheral blood sample were collected from each patient and analysed in a 3-part semiautomated haematology analyser and PVI were tabulated.

\section{RESULTS}

All three Platelet indices, i.e. Mean Platelet Volume (MPV), Platelet Distribution Width (PDW) and Platelet to Large Cell Ratio (PLCR) were significantly increased in Group I and II. In group I mean PDW, MPV and P-LCR were $14.17 \mathrm{fL}, 10.73 \mathrm{fL}$ and $29.01 \%$ respectively. In group II mean PDW, MPV and P-LCR were $11.98 \mathrm{fL}, 10.43 \mathrm{fL}$ and $23.43 \%$ respectively. In group III mean PDW, MPV and P-LCR were $11.06 \mathrm{fL}, 9.36 \mathrm{fL}$ and $21.36 \%$ respectively. Cut off values for predicting acute coronary event for PDW, MPV and PLCR were $12.85 \mathrm{fL}, 9.65 \mathrm{fL}$ and $22.75 \%$ respectively.

\section{CONCLUSION}

PVI is routinely available, simple and cost effective tool for predicting possibility of impending acute events as larger platelets can easily be identified during routine haematological analysis and could possibly benefit from preventive treatment.

\section{KEYWORDS}

Coronary Artery Disease, Platelet Volume Indices.

HOW TO CITE THIS ARTICLE: Rigvardhan, Kumar N, Girish R, et al. Correlation of platelet volume indices (PVI) with spectrum of coronary artery disease: a prospective study in Indian scenario. J. Evolution Med. Dent. Sci. 2016;5(35):1969-1972,

DOI: $10.14260 /$ jemds/2016/465

\section{INTRODUCTION}

Coronary Artery Disease (CAD) is the epidemic of the new millennium and occurs mainly due to atherosclerosis and its complications.[1] Rupture of plaque with resultant platelet rich thrombus formation causes the spectrum of CAD from Acute Myocardial Infarction (AMI) to Unstable Angina (UA).[2] Various risk factors such as smoking, hypertension, diabetes, dyslipidaemia, obesity and mental stress significantly increase the chances of developing atherosclerosis and CAD.[1] Platelets are small anucleate heterogeneous blood elements of varying density and size. Their activation is the hallmark of CAD. ${ }^{[2]}$

Financial or Other, Competing Interest: None.

Submission 13-03-2016, Peer Review 09-04-2016,

Acceptance 14-04-2016, Published 29-04-2016.

Corresponding Author:

Dr. Rigvardhan,

Associate Professor,

Department of Pathology,

Command Hospital,

Lucknow-226002.

E-mail: vardhanrig@yahoo.com

DOI: $10.14260 /$ jemds $/ 2016 / 465$
Platelet size is a marker of platelet activity as large platelets are metabolically and enzymatically more active. $[2,3]$ With advent of automated cell counters the Platelet Volume Indices (PVI) like Mean Platelet Volume (MPV), Platelet Distribution Width (PDW) and Platelet Large Cell Ratio (PLCR) and Platelet Count (PC) are routinely available in laboratories. However, these are generally ignored but they can convey very useful information. Platelet activation is indirectly measured via MPV, as it reflects changes in the level of platelet stimulation and/or the rate of platelet production. PDW measures the variance in platelet size, the larger ones being more active.[4] Thus, our aim was to study platelet parameters in the spectrum of CAD and to attempt a clinicopathological correlation.

\section{MATERIALS AND METHODS}

A prospective hospital-based study was carried out on 230 patients over a period of one year. Institutional Ethical Committee clearance and informed consent was taken. 
The Patients Studied were Divided into Groups as Follows

A. Group I: Patients admitted to the intensive care unit or coronary care unit with UA and/or AMI (100 patients).

B. Group II: Patients with stable CAD admitted for coronary angiography or followup for a previous ischemic event (100 patients).

C. Group III: Age and sex matched normal healthy controls with a normal electrocardiogram (30 patients).

Blood (2 mL) was collected in dipotassium EDTA tubes from all the patients by a clean venepuncture, avoiding bubbles and froth. The sample was run within two hours of venepuncture using the Sysmex KX-21 semiautomated cell counter (Japan). Internal and external quality controls were strictly followed. PVI were tabulated.

AMI was diagnosed based detection of rise in cardiac biomarker-Troponin ' $\mathrm{T}$ ' or Creatinine Kinase-MB value with at least one value above 99th percentile of upper limit and evidence of myocardial ischemia based on symptoms of ischemia, Electrocardiograph (ECG) changes indicative of ischemia or development of pathological $Q$ wave in the ECG and imaging evidence of new regional wall motion abnormality or loss of viable myocardium. UA was diagnosed on clinical parameters and ECG changes with no elevation in biomarkers. Group II patients were diagnosed based on evidence of AMI at least 6 weeks prior as per above mentioned criteria. Patients with severe hepatic or renal impairment and malignancy were excluded from the study.

The enrolment period was between March 2015 and Feb 2016.

\section{Statistical Analysis}

Data was analysed using Statistical Package for Social Sciences, version 15.0. Analysis of variance followed by Independent samples ' $\mathrm{t}$ ' test was used for intergroup and between group comparisons. Receiver Operator Curve (ROC) Analysis was performed for derivation of appropriate cut-off values to assess the sensitivity and specificity of different platelet markers. The $\chi^{2}$ test was used and $p$ values of $<0.05$ were taken as significant.

\section{RESULTS}

230 patients were enrolled in our study. All PVI parameters generated by the Sysmex KX 21 analyzer were statistically analysed. The mean (SD) age of the patients in group I was $63.16 \pm 5.72$ years, in group II $-65.12 \pm 8.09$ years and group III$64.50 \pm 7.94$ years with an equal sex predilection (Male-tofemale ratio, 1:1). CAD occurs one decade earlier in Asian population than in developed countries and is equally prevalent among premenopausal women. ${ }^{[4]}$ In our study, risk factors were evaluated and were evenly distributed. No significant difference among groups was observed with respect to a particular risk factor. Although, any particular risk factor was not significant, but presence of risk factors was significantly higher in group I and group II as compared to controls (Table 1).

Mean PDW, MPV and P-LCR in group I was $14.17 \pm 1.47 \mathrm{fL}$, $10.73 \pm 1.29 \mathrm{fL}$ and $29.01 \pm 4.72 \%$ respectively. In group II mean PDW, MPV and P-LCR was $11.98 \pm 1.45 \mathrm{fL}, 10.45 \pm 1.90 \mathrm{fL}$ and $23.43 \pm 5.74 \%$ (Fig. 1).
Statistically significant increase in MPV, PDW and P-LCR were observed in Group I and II compared to control group $(\mathrm{P}<0.001)$ (Table 2). Intergroup platelet indices were further statistically analysed (Table 3). All the comparisons revealed statistically significant inter-group differences for PVI except MPV in group I versus group II.

ROC curve for PDW, MPV and P-LCR (Fig. 2) when predicting AMI in patients was constructed and AUC was found to be $0.877,0.664$ and 0.790 respectively $(95 \% \mathrm{CI})$. Their sensitivity and specificity with cut off values are summarized in Table 4. Comparison of PDW, MPV and P-LCR in AMI and controls in different studies in Indian scenario are summarized in Table 5.

\begin{tabular}{|c|c|c|c|c|c|}
\hline Groups & $\begin{array}{c}\text { Group } \\
\text { I }\end{array}$ & $\begin{array}{c}\text { Group } \\
\text { II }\end{array}$ & $\begin{array}{c}\text { Group } \\
\text { III }\end{array}$ & $\boldsymbol{\chi}^{\mathbf{2}}$ & P \\
\hline Hypertension & 17 & 15 & 6 & 0.176 & 0.916 \\
\hline Diabetes & 22 & 19 & 7 & 0.469 & 0.791 \\
\hline Smokers & 16 & 14 & 5 & 0.328 & 0.849 \\
\hline Dyslipidaemia & 23 & 17 & 6 & 1.700 & 0.427 \\
\hline Obesity & 3 & 2 & 0 & 1.266 & 0.531 \\
\hline Nil & 19 & 33 & 6 & 24.71 & $<0.001$ \\
\hline \multicolumn{7}{|c|}{ Table 1: Comparison of Different Risk Factors } \\
Among Study Groups \\
\hline
\end{tabular}

\begin{tabular}{|c|c|c|c|c|}
\hline & $\begin{array}{c}\text { Group I } \\
\text { (n=100) } \\
\text { (AMI/UA } \\
\text { Patients) }\end{array}$ & $\begin{array}{c}\text { Group II } \\
\text { (n=100) } \\
\text { (Stable MI } \\
\text { Patients) }\end{array}$ & $\begin{array}{c}\text { Group III } \\
\text { (n=40) } \\
\text { (Controls) }\end{array}$ & $\begin{array}{c}\text { Statistical } \\
\text { Significance }\end{array}$ \\
\hline Age & $63.16 \pm 5.72$ & $65.12 \pm 8.09$ & $64.50 \pm 7.94$ & $\begin{array}{c}\mathrm{F}=1.912 ; \\
\mathrm{p}=0.150(\mathrm{NS})\end{array}$ \\
\hline $\begin{array}{c}\text { PDW } \\
\text { (fL) }\end{array}$ & $14.17 \pm 1.47$ & $11.98 \pm 1.45$ & $11.06 \pm 1.31$ & $\begin{array}{c}\mathrm{F}=91.19 ; \\
\mathrm{p}<0.001(\mathrm{~S})\end{array}$ \\
\hline $\begin{array}{c}\text { MPV } \\
\text { (fL) }\end{array}$ & $10.73 \pm 1.29$ & $10.45 \pm 1.90$ & $9.36 \pm 0.96$ & $\begin{array}{c}\mathrm{F}=11.47 ; \\
\mathrm{p}<0.001(\mathrm{~S})\end{array}$ \\
\hline $\begin{array}{c}\text { P- } \\
\text { LCR } \\
\text { (\%) }\end{array}$ & $29.01 \pm 4.72$ & $23.43 \pm 5.74$ & $21.36 \pm 4.47$ & $\begin{array}{c}\mathrm{F}=44.47 ; \\
\mathrm{p}<0.001(\mathrm{~S})\end{array}$ \\
\hline
\end{tabular}

Table 2: Platelet Indices and CAD (Values are Mean $\pm S D$ )

\begin{tabular}{|c|c|c|c|c|c|c|}
\hline \multirow{2}{*}{} & \multicolumn{2}{|c|}{ Group I vs II } & \multicolumn{2}{c|}{ Group I vs III } & \multicolumn{2}{c|}{ Group II vs III } \\
\cline { 2 - 7 } & 't' & 'p' & 't' & 'p' & 't' & 'p' \\
\hline PDW (FL) & 10.64 & $<0.00$ & 11.58 & $<0.001$ & 3.46 & 0.001 \\
\hline MPV & 1.19 & 0.236 & 6.05 & $<0.001$ & 3.46 & 0.001 \\
\hline P-LCR & 7.51 & $<0.001$ & 8.80 & $<0.001$ & 2.04 & 0.043 \\
\hline \multicolumn{2}{|c|}{ Table 3: Between Group Differences in Platelet Indices } \\
\hline
\end{tabular}

\begin{tabular}{|c|c|c|c|c|}
\hline & $\begin{array}{c}\text { Area } \\
\text { Under } \\
\text { Curve }\end{array}$ & $\begin{array}{c}\text { Projected } \\
\text { Cut-off } \\
\text { Value }\end{array}$ & $\begin{array}{c}\text { Calculated } \\
\text { Sensitivity }\end{array}$ & $\begin{array}{c}\text { Calculated } \\
\text { Specificity }\end{array}$ \\
\hline $\begin{array}{c}\text { PDW } \\
\text { (FL) }\end{array}$ & 0.877 & $>12.85$ & $80 \%$ & $77.1 \%$ \\
\hline MPV & 0.664 & $>9.65$ & $77 \%$ & $51.4 \%$ \\
\hline $\begin{array}{c}\text { P- } \\
\text { LCR }\end{array}$ & 0.790 & $>22.75$ & $97 \%$ & $62.9 \%$ \\
\hline \multicolumn{4}{|c|}{ Table 4: Discriminant Cut-Off Values and their } \\
Calculated Sensitivity and Specificity \\
(ROC Analysis) for AMI
\end{tabular}




\begin{tabular}{|c|c|c|c|c|c|c|c|c|c|}
\hline \multirow{2}{*}{ Publication } & \multicolumn{3}{|c|}{ MPV } & \multicolumn{3}{c|}{ PDW } & \multicolumn{3}{c|}{ P-LCR } \\
\cline { 2 - 29 } & Cases & Control & p Value & Cases & Control & p Value & Cases & Control & p Value \\
\hline $\begin{array}{c}\text { M.M. Khandekar } \\
\text { et al (2006).[1] }\end{array}$ & 10.43 & 9.2 & $<0.001$ & 13.19 & 10.75 & $<0.001$ & 29.4 & 20.65 & $<0.001$ \\
\hline $\begin{array}{c}\text { Vitthal Khode } \\
\text { et al (2012).[5] }\end{array}$ & 9.65 & 9.21 & 0.025 & 10.84 & 10.35 & 0.376 & 21.58 & 19.93 & 0.315 \\
\hline $\begin{array}{c}\text { KN Desai } \\
\text { et al (2013).[4] }\end{array}$ & 11.2 & 9.30 & $<0.001$ & 14.3 & 11.3 & $<0.001$ & 28.6 & 19.86 & $<0.001$ \\
\hline Present Study & 10.73 & 9.36 & $<0.001$ & 14.17 & 11.06 & $<0.001$ & 29.01 & 21.36 & $<0.001$ \\
\hline
\end{tabular}

Table 5: Comparison of PDW, MPV and P-LCR in AMI and Controls in Different Studies in Indian Scenario

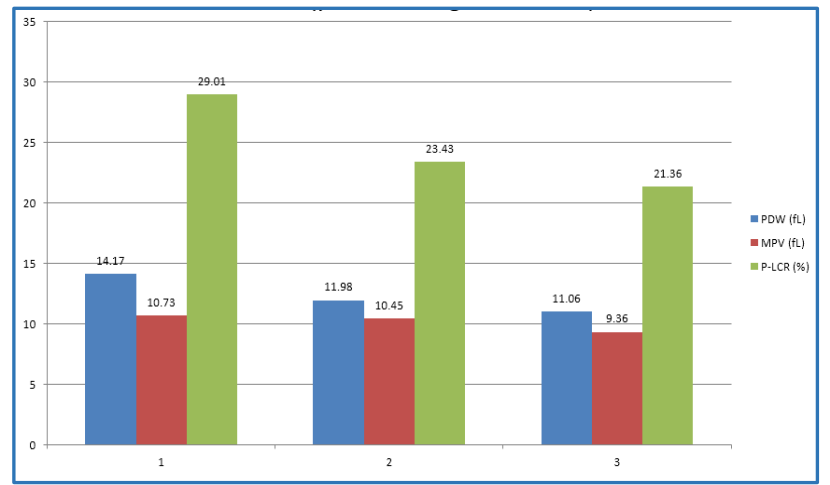

Fig. 1: Platelet Volume Indices in all Patients (Groups I, II, and III). MPV (Mean Platelet Volume); PDW (Platelet Distribution Width); P-LCR (Platelet Large Cell Ratio)

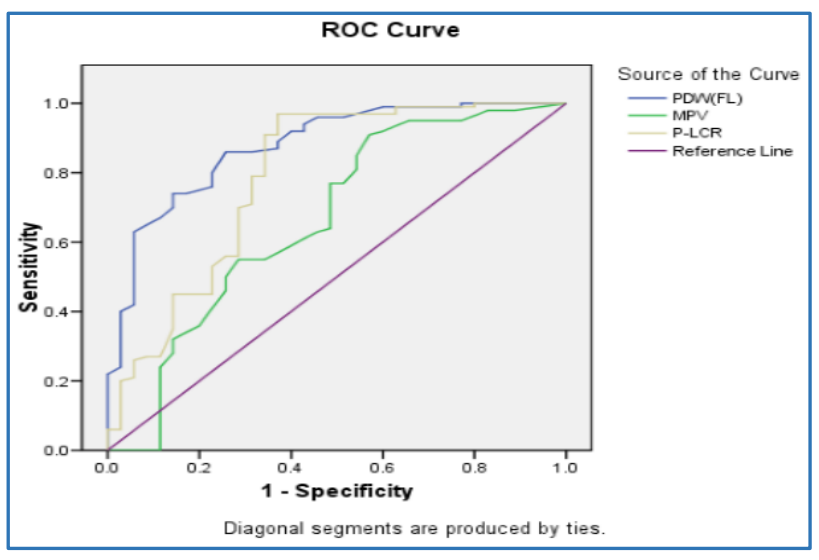

Fig. 2: ROC Curve for PDW, MPV and P-LCR in AMI

\section{DISCUSSION}

The findings of the present study revealed significantly higher MPV, PDW and P-LCR values in patients with AMI/UA when compared to the control group $(\mathrm{P}<0.01)$. According to previous studies, increased prothrombotic activity can be ascertained by carefully analysing PVI and the presence of large platelets reflected as high MPV are associated with a greater aggregation potential causing thrombus formation, which is a risk factor for AMI, UA and stroke.[1,5,6] Our results corroborate with previous findings that underlines the essential role of platelets in AMI and UA, suggesting that MPV and PDW are related to platelet anisocytosis including macroplatelets that may contribute as independent haematological marker to cardiovascular risk.[7]

Generalized platelet activation is the hallmark of an acute coronary event. Platelet consumption increases at the coronary atherosclerotic plaque causing larger platelets to be released from the bone marrow.
The fact that this increase persists even after weeks supports the view that platelet volume is chronically larger in the AMI group. ${ }^{[8]}$ This suggests that PVI, particularly MPV are indicators of the degree of damage already done and that these markers maintain their strength and predictive value for a long time.[1] However, Pizzulli et al did not find any correlation between the time span between MI and measurement of MPV.[9] They suggested that MPV does not change during the acute phase reaction, but is determined by other factors.

Various studies have correlated the association between the type and site of infarct and MPV. Khandekar et al[1] and Desai et al[ ${ }^{4]}$ did not find any correlation between type and size of infarct with MPV, but Martin et al[8] and Cameron et al[10] reported significant correlation between MPV and site and size of infarct. Association of PVI with mortality was studied by Martin et al and found that MPV was significantly higher in those patients who died of MI compared with survivors. ${ }^{[8]}$ Higher MPV values have been reported in patients with UA than those with MI.[11,12] However, we found no such difference between patients with UA and AMI. Using logistic regression analysis of MPV quartiles, we found that a value of $>9.65 \mathrm{fL}$ was a significant risk for developing AMI in patients with CAD, whereas a figure of $>9.6 \mathrm{fL},>9.4 \mathrm{fL},>9.25 \mathrm{fL},>11.6 \mathrm{fL}$ was determined by Khandekar et al[1] Desai et al[4] Khode et al[5] and Endler et al[13] respectively. Value of $>9.65 \mathrm{fL}$ as found in our study had sensitivity and specificity of $77 \%$ and $51.4 \%$ respectively.

Role of other PVI such as PDW in patients with CAD and acute coronary events is yet to be explored. But it was significantly higher in AMI/UA as compared to controls. $[1,4,6]$ We also found significantly increased PDW in AMI/UA. Using logistic regression analysis of PDW quartiles, we found value of more than $12.65 \mathrm{fL}$ having sensitivity and specificity of $80 \%$ and $77.1 \%$ respectively.

PDW is a measure of platelet anisocytosis with higher value indicating reactive platelet population.[14]

P-LCR reflects platelet larger cell ratio with larger platelets being more reactive and contribute to vaso-occlusive events in patients, especially with dyslipidaemia and thus PLCR may be used as an indicator of risk factor for thromboembolic ischemic events.[15] We found P-LCR to be significantly increased in AMI/UA group and value more than $22.75 \%$ had sensitivity and specificity of $97 \%$ and $62.9 \%$ respectively.

\section{CONCLUSION}

In conclusion, the results of the present study appear to confirm and substantiate that an increase in PVI contributes to the prothrombotic state in AMI/UA and that larger platelets may also play a specific role in MI. 
Thus, the use of PVI can be an important tool in the assessment and follow-up of cardiac patients because these indices are readily provided when a complete blood count is requested by the physician.

Future studies including the use of MPV, PDW and P-LCR as a cost effective tool in a risk stratification to predict acute coronary events as well as the response to medical interventions are worthy of consideration.

\section{REFERENCES}

1. Khandekar MM, Khurana AS, Deshmukh SD, et al. Platelet volume indices in patients with coronary artery disease and acute myocardial infarction: an Indian scenario. J Clin Pathol 2006;59(2):146-9.

2. Trip MD, Cats VM, van Capelle FJL, et al. Platelet hyperreactivity and prognosis in survivors of myocardial infarction. New Engl J Med 1990;322(22):1549-54.

3. Thompson CB, Eaton KA, Princiotta SM, et al. Sizedependent platelet subpopulation: relationship of platelet volume to ultrastructure, enzymatic activity and function. Br J Haematol 1982;50(3):509-19.

4. Desai KN, Patel K, Shah M, et al. A study of platelet volume Indices (PVI) in patients of coronary artery disease and acute myocardial infarction in tertiary care hospital. International Journal of Advanced Research 2013;1(6):185-91.

5. Khode V, Sindhur J, Kanbur D, et al. Mean platelet volume and other platelet volume indices in patients with stable coronary artery disease and acute myocardial infarction: a case control study. J Cardiovasc Dis Res 2012;3(4):2725.

6. Costa SC, de Matos Vinagre CG, Chacra APM, et al. Platelet indices in patients with acute coronary syndrome. Journal of Biosciences and Medicines 2015;3(11):71-6.
7. Chu H, Chen WL, Huang CC, et al. Diagnostic performance of mean platelet volume for patients with acute coronary syndrome visiting an emergency department with acute chest pain: the Chinese scenario. Emergency Medicine Journal 2011;28:569-74. http://dx.doi.org/10.1136 /emj.2010.093096.

8. Martin JE, Bath PMW, Burr ML. Influence of platelet size on outcome after myocardial infarction. Lancet 1991;338(8780):1409-11.

9. Pizzulli L, Yang A, Martin JF, et al. Changes in platelet size and count in unstable angina compared to stable angina or non-cardiac chest pain. Eur Heart J 1998;19:80-4.

10. Cameron HA, Phillips R, Ibbatson RM, et al. Platelet size in myocardial infarction. BMJ 1983;287(6390):449-51.

11. Mathur A, Robinson MS, Cotton J, et al. Platelet reactivity in acute coronary syndromes: evidence for differences in platelet behaviour between unstable angina and myocardial infarction. Thromb Haemost 2001;85(6):989-94.

12. Senaran H, Ileri M, Altinbas A, et al. Thrombopoietin and mean platelet volume in coronary artery disease. Clin Cardiol 2001;24(5):405-8.

13. Endler G, Klimesch A, Plassmann HS, et al. Mean platelet volume is an independent risk factor for myocardial infarction but not for coronary artery disease. $\mathrm{Br} \mathrm{J}$ Haematol 2002;117(2):399-404.

14. Ranjith MP, Divya R, Mehta VK, et al. Significance of platelet volume indices and platelet count in ischaemic heart disease. J Clin Pathol 2009;62(9):830-3.

15. Grotto HZ, Noronha JF. Platelet larger cell ratio (P-LCR) in patients with dyslipidaemia. Clin Lab Haematol 2004;26(5):347-9. 